\title{
The Real Options Solution To A Cost-Of-Capital Dilemma
}

\author{
David Eagle, Eastern Washington University, USA \\ David L. Senteney, Ohio University, USA \\ Dean Kiefer, Eastern Washington University, USA
}

Arsen Djatej, Colorado State University-Pueblo, USA

\begin{abstract}
The required rate of return should equal the average expected return in the market for the same level of risk. However, firms should only accept such projects with expected returns that exceed this required rate of return. This contradicts our first statement that the required rate of return equals this average expected return for the market. We study this possible paradox in the context of a stochastic general-equilibrium model with endogenous prices. We find that the capitalization of the real options involved in this model explains away this contradiction or paradox.
\end{abstract}

Keywords: cost of capital, real options, capital budgeting, general equilibrium financial theory, expected returns, rate-of-return paradox

\section{INTRODUCTION}

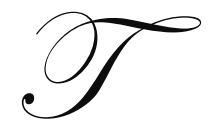

his research utilizes a general-equilibrium stochastic model in trying to understand that firms only accept such projects with expected returns that exceed this required rate of return. While we did not initially intend to look at real options, we found that real options provide part of the solution to this puzzle. Clearly, if a firm is facing a capital budgeting decision in the future, there is an option associated with that decision. The firm has the option to undertake that project. Whether the firm decides to undertake the project depends whether or not the option turns out to be in the money at the time the decision is to be made. However, prior to the time the decision needs to be made, the option will have some value. By taking into account the option value, both prior to the decision time and at the decision time, we found the answer to the dilemma.

The theory of real options relates to the possible investments in fixed assets and similar to financial options in structure. The most widely accepted definition of real options comes from "Expectations Investing. Reading Stock Prices for Better Returns" by Rappaport and Mauboussin. According to them, "real-options approach applies financial options theory to real investments, such as manufacturing plants, product line extensions, and research and development. A financial option gives the owner the right, but not the obligation, to buy or sell a security at a given price. Analogously, companies that make strategic investments have the right, but not the obligation, to exploit these opportunities in the future" (Rappaport \& Mauboussin, 2003, 118). Rita McGrath continues this theory and implies that "just as the purchase of an option contract conveys the right, but not the obligation, to purchase the underlying asset on which the contract is written, investment in a real option conveys the opportunity to continue investment. If investments are staged so that expenditures end under poor conditions, losses can be contained (McGrath, 1999, 13)

The realization of the importance of real options to capital budgeting is not new. Davis (2002) notes that the decision to invest in a project is "similar to exercising a call option; the exercise price is the present value of the cost of the investments, and the underlying asset is the present value of revenues generated by that investment.

The literature on real options points to the option value of the firm's future capital budgeting decisions being capitalized into the value of the firm. Pindyck (1988) notes that a firm's value will be determined from options involving future capital utilization, future investments, and potential future investments. Ottoo (2000) estimated that between $60 \%$ and $99 \%$ of firm value in the internet, biotechnology, computers, and pharmaceutical industries come from the value of growth options. 
Many models in the real options literature assume exogenous stochastic prices that follow geometric Brownian motion (For example, Davis, 2002). However, prices are endogenous in a general equilibrium. Some models do assume endogenous prices that depend on some random underlying process (For example, Hull, 2002). However, these models only can handle one underlying random process for each option, which does not allow a very realistic option valuation path over time. This paper's model includes three underlying random processes for each project. However, to work out the mathematics involved, we needed to simplify the model to discrete time. The prices are endogenously determined in this paper's one-period, rational expectations, general equilibrium model with consumption both at the beginning and the end of the period. Randomness enters into the model through real productivity and the estimation of that productivity. The next section presents that framework.

\section{MODEL FRAMEWORK}

Only unsystematic risk exists in the model as systematic risk would merely distract from what is important. This is a one-period model with a beginning and an end. There are many consumers, many firms, and many projects that can be undertaken by the firms.

Consumption occurs both at the beginning of the period and at the end of the period. Where $\rho$ is the rate of time preference, which is the same for all consumers, and $C_{j t}$ is the consumption by consumer $\mathrm{j}$ at time t, each consumer $\mathrm{j}$ maximizes the expected value of his/her risk-averse utility function, $U_{j}\left(C_{j 0}\right)+\frac{U_{j}\left(C_{j 1}\right)}{1+\rho}$, subject to its budget constraints involving bonds, stocks, options, and possibly other assets.

Consumers are endowed with consumption units at times 0 and/or time 1. Depending on the specific assumptions of the particular variation to the model, consumers may also have other endowments such as the stock of firms, options to particular projects, or particular productive assets like land or capital. Also, the firms themselves may be endowed with consumption units in some variations of the model. While we do assume only one share of stock exists for each firm, fractional shares can be traded.

By assuming that the total endowment of time 0's consumption good is at least equal to the number of projects, which would be the demand for the good by the firms if they undertook all the projects, the riskfree interest rate (r) will equal the rate of time preference. Also, since index investing is possible and "many" firms exist, consumers will be able to diversify away almost all their risk since all risk is unsystematic risk. Therefore, the required rate of return on equity equals the riskfree interest rate. Hence, the cost of capital in this simple model equals the riskfree interest rate.

Firms consider undertaking projects. Each project $\mathrm{i}$ involves taking one consumer unit at time 0 in order to produce $v_{i}$ units of the consumption good at time 1. One may think about these projects as trees. Firms have the choice of cutting down the tree for consumption now or leaving the tree to grow for one period when they expect the tree to be bigger. At time 0 , the firm does not know $v_{i}$, but does observe a related variable $y_{i}$, which we will show is the firm's best estimate of $v_{i}$. Three random variables affect $v_{i}$ and $y_{i}$ as shown below:

$$
\begin{aligned}
& v_{i}=\frac{u_{i}+\eta_{i}}{2} \\
& y_{i}=\frac{u_{i}+\varepsilon_{i}+2}{4}
\end{aligned}
$$

where $\mathrm{u}_{\mathrm{i}}, \eta_{\mathrm{i}}$, and $\varepsilon_{\mathrm{i}}$ are independent standard exponential random variables.

Equation (1) states that the value of the project at the end of the period is the average of two random variables: $u_{i}$ which is somewhat predictable and $\varepsilon_{i}$ which is totally unpredictable. Equation (2) states that the firm's estimate of the value of the project at the end of the period is influenced by the somewhat predictable random 
variable $u_{i}$ and another totally unpredictable random variable $\varepsilon_{i}$. It is important to realize that $\eta_{i}$, and $\varepsilon_{i}$ are different random variables, both of which cause the firm's estimate of the value of the project $\left(y_{i}\right)$ to be less than perfect. The firm's estimate of the value of the project $\left(y_{i}\right)$ can only help predict $u_{i}$ not $\eta_{i}$. Also, because of the random variable $\varepsilon_{i}$, the firm is unable to perfectly predict $u_{i}$.

When the firm analyzes the project it will compute its estimate $y_{i}$ and then deduce from $y_{i}$ the value of $u_{i}$ and hence $v_{i}$. The appendix derives the following properties for each project $\mathrm{i}$ :

$$
\begin{aligned}
& \mathrm{E}\left[v_{i}\right]=1 \\
& \mathrm{E}\left[v_{i} \mid y_{i}\right]=y_{i} \\
& E\left[\tilde{v}_{i}\right]=(1+r)\left(1+e^{2-4(1+r)}\right)
\end{aligned}
$$

where $\tilde{v}_{i} \equiv \max \left(y_{i}, 1+r\right)$. The variable $\tilde{v}_{i}$ is the expectation at time $0^{+}$of the amount of the consumption good at time 1 that would result from the optimal decision at time $0^{+}$concerning project $i$. If the firm's estimate $y_{i}$ exceeds $1+\mathrm{r}$, then the firm will invest in the project and $\tilde{v}_{i}=y_{i}$. On the other hand, if the firm's estimate of $y_{i}$ is less than $1+\mathrm{r}, \tilde{v}_{i}=1+r$ since the firm would not invest in the project as it could lend the consumption good for the period instead of investing it.

The expectations in (3) and (5) are the expectations at time $0^{-}$which is before the firm observes $y_{i}$. Of course, the expectation in (4) is once the firm has observed $y_{i}$.

\section{MODEL 1: OPTIONS ATTACHED TO FIRMS WITH EQUITY FINANCING}

In this model, the number of firms equals the number of projects and each firm is endowed with one consumer unit. Consumers are in turn endowed with consumer units and the shares of stock in the firms. At time 0 a sequence of markets takes place. At time $0^{-}$, the pre-analysis stock market takes place. Between time $0^{-}$and time $0^{+}$, each firm $\mathrm{i}$ analyzes its project $\mathrm{i}$ and then publishes $y_{i}$, which is the firm's estimate of the consumption good resulting from the project at time 1 . A post-analysis stock market takes place at time $0^{+}$.

Let $P_{i}^{-}$be the pre-analysis price of stock and let $P_{i}^{+}$be the post-analysis price of stock. The post-analysis price of stock will be the present value of $\tilde{v}_{i}$ :

$$
P_{i}^{+}=\frac{\tilde{v}_{i}}{1+r}=\frac{\max \left[y_{i}, 1+r\right]}{1+r}
$$

The NPV of the project will equal $\frac{y_{i}}{1+r}-1$, where the -1 represents the consumer unit that cannot be consumed if the firm goes ahead with the project. If NPV $>0$, which means $y_{i}$ exceeds $1+r$, then the firm will undertake the project and $P_{i}^{+}$will equal $\frac{y_{i}}{1+r}$. Otherwise, NPV $<0$ and the firm will not undertake the project. If NPV is negative, then $P_{i}^{+}=1$, which represents the consumer unit that the firm will return to its stockholders. The firm is using $r$ as the cost of capital and $r$ is the expected return on the firm based on the post-analysis price of stock $P_{i}^{+}$.

The pre-analysis price of stock should equal the pre-analysis expected value of $P_{i}^{+}$, which by equation (5) equals: 


$$
P_{i}^{-}=E\left[P_{i}^{+}\right]=\frac{E\left[\tilde{v}_{i}\right]}{1+r}=\left(1+e^{2-4(1+r)}\right)
$$

The term $e^{2-4(1+r)}$ is the value of the option of the firm to undertake project i. Prior to the analysis of the project, the value of this option will be capitalized into the price of the stock.

Remember the cost-of-capital puzzle that motivated this analysis. We said that the required rate of return on a project should equal the average expected return in the market for similar risks. Since we assume no systematic risk in our model, the average expected return in the market equals the riskfree return. Therefore, the required rate of return should equal the riskfree return.

The other part of the cost-of-capital puzzle was that firms would only accept projects that had positive net present values, where the expected return on the projects exceed the required rate of return. In this model, the firms do only accept projects with positive NPV, where $\frac{y_{i}}{1+r}-1$ exceeds zero. In a positive NPV project, the expected return on the project $\left(y_{i}-1\right)$ exceeds the required rate of return (r).

At first glance, it would appear that if firms only accept projects where the expected return on the project exceeds the required rate or return, then the required rate of return cannot equal the average expected return in the market. However, this first glance confuses two different concepts of return: (a) the expected return on the project and (b) the expected return on the stock. To see this distinction in our model, look at time $0^{+}$when the firm has observed $y_{i}$ and assume that NPV $>0$ which means $\frac{y_{i}}{1+r}>1$. To compute the expected return on the project, we need to take into account the incremental net cash inflows. The net incremental cash inflow of the project at time 0 is 1 consumption unit. Therefore, the expected return on the project would equal $\frac{y_{i}-1}{1}$ which is just $y_{i}-1$. However, to compute the expected return on the stock, we need to use the price of the stock instead of the time-0 cash outflow of one consumption unit. Therefore, the expected return on the stock would equal $\frac{y_{i}-P_{i}^{+}}{P_{i}^{+}}$. Since by equation (6), $P_{i}^{+}=\frac{y_{i}}{1+r}$ when $\frac{y_{i}}{1+r}>1$, the expected return on the stock would equal $\mathrm{r}$, the riskfree return. Thus, even though firms will accept only projects with positive NPVs, where the expected return on the projects exceeds the required rate of return, the average expected returns on the stocks still equals the required rate of return. The reason that the expected return on the project differs from the expected return on the stock is that the positive $\mathrm{NPV}$ is reflected in the value of the stock at time $0^{+}$.

Another issue clouding the cost-of-capital puzzle has to do with the different time frames $0^{-}$and $0^{+}$. In both time frames, the expected return on the stock equals $r$, the riskfree interest rate. At time 0 , there is a positive value to the option of undertaking the project which is reflected in the value of the stock at time $0^{-}$. The expected return on the stock equals $\frac{E\left[\tilde{v}_{i}\right]-P_{i}^{-}}{P_{i}^{-}}$, which by equation (7) implies an expected return of r.

This model clearly distinguishes the stock values between times $0^{-}$and $0^{+}$and distinguishes the return on the project from the return on stock. We therefore conclude that the required rate of return can equal the average expected return on stocks in the market even though firms will accept projects where the expected return on the projects exceed the required rate of return. The difference between the expected return on stocks and the expected return on projects is that the positive NPVs are capitalized into the price of stocks. 


\section{MODEL 2: OPTIONS ATTACHED TO FIRMS WITH DEBT FINANCING)}

Model 2 is the same as model 1 except that the firm relies solely on debt financing and each firm has no endowment of the consumer good. Each firm $\mathrm{i}$ is, however, endowed with the exclusive right (but not the obligation) to undertake project $i$. The firm will obtain the consumer good if the firm undertakes the project by borrowing the consumer good from the consumers.

The post-analysis price of the stock of firm i will equal the net present value (NPV) of project i:

$$
P_{i}^{+}=\frac{\tilde{v}_{i}}{1+r}-1=\frac{\max \left[y_{i}, 1+r\right]}{1+r}-1
$$

If $\mathrm{y}_{\mathrm{i}}$ exceeds $1+\mathrm{r}$, then the firm will undertake the project and $P_{i}^{+}$will equal $\frac{y_{i}}{1+r}-1$; otherwise, the firm will not undertake the project and $P_{i}^{+}=0$. The firm is using $\mathrm{r}$ as its hurdle rate and $\mathrm{r}$ is the expected return on the firm based on the post-analysis price of stock $P_{i}^{+}$.

The pre-analysis price of stock should equal the pre-analysis expected value of $P_{i}^{+}$, which by equation (5) equals:

$$
P_{i}^{-}=E\left[P_{i}^{+}\right]=\frac{E\left[\tilde{v}_{i}\right]}{1+r}-1=e^{2-4(1+r)}
$$

This says that the pre-analysis value of the stock equals the value of the option to undertake the project. In other words, prior to the analysis of the project, the value of the firm is the value of the option to undertake the project.

Again, the cost-of-capital puzzle is resolved in this model by distinguishing between the expected return on the project and the expected return on the stock. The expected return on the project is $\frac{y_{i}-1}{1}$ which is just $y_{i}-1$. On the other hand, the expected return on the stock is $\frac{y_{i}-P_{i}^{+}}{P_{i}^{+}}$. Since by equation (8), $P_{i}^{+}=\frac{y_{i}}{1+r}$ when $\frac{y_{i}}{1+r}>1$, the expected return on the stock would equal $\mathrm{r}$, the riskfree return.

\section{MODEL 3: UNATTACHED OPTIONS}

Models 1 and 2 seem to lack competition in that each firm i had a monopoly in project i. To change the model so we can interpret it in a more competitive environment, Model 3 assumes that firms do not initially exist, but instead issue stock after the analysis of the projects. Consumers, however, are endowed not only with consumption goods, but also with the rights (but not the obligation) to undertake the projects. In other words, consumers are endowed with the options to undertake the projects.

Consumers can trade options in both the pre-analysis and post-analysis options market,. In the postanalysis options market, firms purchase the options to those projects that their analyses indicate are worthwhile. Simultaneously when the firms purchase the options, they will issue their stock. The price of their stock will equal the price of the option plus one consumption unit for each project the firm plans to undertake. The expected return on the stocks will equal the cost of capital. Thus, the firms expect to make only a normal (competitive) return. 
The pre-analysis and post-analysis prices of option i are:

$$
\begin{aligned}
& X_{i}^{-}=e^{2-4(1+r)} \\
& X_{i}^{+}=\frac{\max \left[y_{i}, 1+r\right]}{1+r}-1
\end{aligned}
$$

where $X_{i}^{-}$is the pre-analysis price of the option and $X_{i}^{+}$is the post-analysis price of the option. (These option prices are the same as the prices of stock in model 2). Note that if $y_{i}<1+r$, the post-analysis price of the option is zero.

Because the value of the option is separate from the value of the firm's stock, the NPV of the project can never exceed zero, and the expected return on the project will never exceed the required rate of return. The NPV of the project equals $\frac{y_{i}}{1+r}-1-X_{i}^{+}$. While the project should be undertaken if $\frac{y_{i}}{1+r}>1$, the firm will have to purchase the right to undertake the project for $X_{i}^{+}$. By (11), the NPV will equal 0 whenever $\frac{y_{i}}{1+r}>1$. Thus in Model 3, the expected return of the project (net of the cost of the option) will at most equal $r$, the riskfree return.

\section{MODEL 4: OPTIONS ATTACHED TO LAND}

Model 3 merely transferred the monopoly each firm had to undertake a project to the consumers. Model 4 is the same as Model 3 except consumers are endowed with parcels of land instead of options per se. Each parcel of land has one consumption unit on it. Each project $\mathrm{i}$ involves using land parcel $\mathrm{i}$ to grow the existing consumption unit. The pre-analysis and post-analysis prices of land will be

$$
\begin{aligned}
& L_{i}^{-}=1+e^{2-4(1+r)} \\
& L_{i}^{+}=\frac{\max \left[y_{i}, 1+r\right]}{1+r}
\end{aligned}
$$

If $y_{i}>1+r$, the firm will leave the consumption unit on the land to grow one more period. On the other hand, if $y_{i}<$ $1+r$, the consumption unit will be taken from the land and the land left fallow. These land prices are the same as the option prices in Model 3. Instead of the option values being capitalized into the value of the firm, they are instead capitalized into the value of the land.

\section{MODEL 5: OPTIONS ATTACHED TO CAPITAL}

Instead of land or options, consumers in this model are endowed with another asset, which we will call capital. Each project $\mathrm{i}$ involves using capital asset $\mathrm{i}$ and one consumer good to produce consumer goods one period from now.

The pre-analysis and post-analysis prices of capital asset $i$ are:

$$
\begin{aligned}
& K_{i}^{-}=e^{2-4(1+r)} \\
& K_{i}^{+}=\frac{\max \left[y_{i}, 1+r\right]}{1+r}-1
\end{aligned}
$$


where $K_{i}^{-}$is the pre-analysis price of capital asset i and $K_{i}^{+}$is the post-analysis price of capital asset i. These prices are the same as the option prices in Model 3. In this model, the value of the option to undertake the project is capitalized into the capital asset. If $\mathrm{y}_{\mathrm{i}}>1+\mathrm{r}$, the firm will purchase the capital asset and one unit of the consumption good to invest in the project. If $\mathrm{y}_{\mathrm{i}}<1+\mathrm{r}$, the firm will idle the capital asset.

\section{MODEL 6: ASYMMETRIC INFORMATION}

In the previous models, we avoided the complication of asymmetric information by assuming the firm's analysis results were publicized. If the firm keeps that information to itself, then the owners of the option for the project or the owners of the assets to which that option is attached would have more difficulty ascertaining the true value of their asset. This next model, model 6 , assumes that the only thing the firms publicize is the decision whether to invest or not, not the expected value of that investment. This model will be an extension of Model 1, where the public's expectation of the NPV of the project is capitalized into the price of the stock.

If at time $0^{+}$the firm does not undertake the project, $P_{i}^{+}$will equal 1 , which is the consumption unit that will be returned to the stockholders. On the other hand, if the firm does undertake the project,

$P_{i}^{+}=\frac{E\left[\tilde{v}_{i} \mid \text { project } \mathrm{i} \text { is undertaken }\right]}{1+r}$

This price will exceed 1 but may differ from $\frac{y_{i}}{1+r}$ because the firm does not publish its realization of $y_{i}$. Even so, the cost-of-capital puzzle is again resolved by the distinction between the expected return on the project and the expected return on stock. The firm's expectation of the return on the project will be $\frac{y_{i}-1}{1}$ which for a positive NPV project will exceed the riskfree interest rate. However, the public's expected return on the stock equals $\frac{E\left[\tilde{v}_{i} \mid \text { project } \mathrm{i} \text { is undertaken }\right]-P_{i}^{+}}{P_{i}^{+}}$

By (16) this implies that the public's expected return on the stock equals $\mathrm{r}$, the riskfree return. Thus, even though the firm only accepts projects where its expected return on the project exceeds the required rate of return, the required rate of return still equals the public's expected return on stock.

\section{SUMMARY AND REFLECTIONS}

Our model helped us resolve the cost-of-capital puzzle that motivated this paper. We found that the required rate of return did, in fact, equal the expected return on stock in the economy, but the firms only accepted projects that had expected returns which exceeded the required rate of return. The stochastic nature of our model resulted in a real option being associated with each project. The value of that option, either at the decision date or prior to expiration, needed to be capitalized into either the price of the stock of the firm or into some other asset. When that value was capitalized into the price of the stock of the firm, the cost-of-capital puzzle was resolved by clearly distinguishing between the expected return on the project and the expected return on the stock.

\section{AUTHOR INFORMATION}

David Eagle is an Associate Professor of Finance at Eastern Washington University in Spokane and Cheney, Washington. He received his Ph.D. in Economics from the University of Minnesota in 1986. His research includes publications on the Stock Market Crash of 1987, index arbitrage, the Federal Funds Rate Market, and inflation indexing. Dr. Eagle's current research includes Corporate Finance/Capital Budgeting Issues, Monetary Economics, and a new type of inflation indexing he and Dale Domian designed, call "Quasi-Real Indexing" that not only efficiently deals with inflation, but also helps mitigate the problems of aggregate-demand-caused recessions. Prior to his pursuing graduate studies, David Eagle earned his Bachelor's Degree in Accounting and Economics and held jobs as an internal auditor at a bank and as an insurance auditor. 
Dean Kiefer is an Associate Professor of Finance at Eastern Washington University. He holds a PhD in Financial Economics from the University of New Orleans, a MA in Economics from the University of Toledo, a MBA from the University of Akron and a BE in Chemical Engineering from Stevens Institute of Technology. He is also a CFA Charterholder. His primary teaching and research interests are in corporate finance and investments.

Professor Arsen Djatej holds a Ph.D. from Ohio University and specializes in Intermediate Accounting, Advanced Accounting, and International Accounting topics, Accounting Information Systems and MBA accounting. Arsen has published articles in journals in the United States and in Europe. His research primarily involves international accounting and taxation with a special focus on the accounting issues in transition economies.

Dr. Senteney has a Ph.D. in Accountancy from the University of Illinois at Urbana-Champaign and specializes in teaching Intermediate Accounting, Advanced Accounting, International Accounting and Financial Statement Analysis topics at graduate and undergraduate levels. Professor Senteney consults in Accounting Accreditation, Graduate Accounting Programs, and Graduate Programs emphasizing the international dimensions of financial reporting and standard setting. Dr. Senteney is widely published in scholarly research journals in areas primarily relating to financial reporting regulation for equity security markets and international standardization of financial reporting requirements.

\section{REFERENCES}

1. Davis, G.A. (2002), "The impact of volatility on firms holding growth options", The Engineering Economist, Vol. 47 No.2, pp.213-31.

2. Hull, John, Options, Futures, and Other Derivatives, $5^{\text {th }}$ Edition, (Prentice Hall: New Jersey), 2002.

3. Luehrman, Timothy, A., Investment Opportunities as Real Options: Getting Started on the Numbers. Harvard Business Review, July-August, 1998.

4. McGrath, Rita Gunther Falling Forward: Real Options Reasoning and Entrepreneurial Failure, The Academy of Management Review, Vol. 24, No. 1 (Jan., 1999), pp. 13-30

5. Ottoo, Richard E (2000), Valuation of Corporate Growth Opportunities: A Real Options Approach, (Routledge Publishers)

6. Pindyck, R., 1988. Irreversible Investment, Capacity Choke, and the Value of the Firm. American Economic Review 78, 969-985.

7. Rappaport, Alfred \& Mauboussin, Michael J. Expectations Investing. Reading Stock Prices for Better Returns, Harvard Business School Press, 2003 


\section{APPENDIX}

This appendix derives the $\mathrm{E}\left[\mathrm{v}_{\mathrm{i}}\right], \mathrm{E}\left[\mathrm{v}_{\mathrm{i}} \mid \mathrm{y}_{\mathrm{i}}\right]$, and $\mathrm{E}\left[\tilde{v}_{i}\right]$. Since $v_{i}=\frac{u_{i}+\eta_{i}}{2}$,

$E\left[v_{i}\right]=\frac{E\left[u_{i}\right]+E\left[\eta_{i}\right]}{2}=\frac{1+1}{2}=1$ since $\mathrm{u}_{\mathrm{i}}$ and $\eta_{\mathrm{i}}$ are standard exponentially distributed.

To determine $\mathrm{E}\left[\mathrm{v}_{\mathrm{i}} \mid \mathrm{y}_{\mathrm{i}}\right]$, we first need to know the conditional probability density function of $\mathrm{u}_{\mathrm{i}}$ given $\mathrm{y}_{\mathrm{i}}$. The joint probability of $\mathrm{u}_{\mathrm{i}}$ and $\varepsilon_{\mathrm{i}}$ is $f\left(u, \varepsilon_{i}\right)=e^{-u_{i}-e_{i}}$ for $\mathrm{u}_{\mathrm{i}} \geq 0$ and $\varepsilon_{\mathrm{i}} \geq 0$ as $\mathrm{u}_{\mathrm{i}}$ and $\varepsilon_{\mathrm{i}}$ are independent standard exponential random variables; this probability density function equals 0 whenever $\mathrm{u}_{\mathrm{i}}$ or $\varepsilon_{\mathrm{i}}$ is less than zero. Since $y_{i}=\frac{u_{i}+\varepsilon_{i}+2}{4}$, the cummulative probability distribution of $\mathrm{u}_{\mathrm{i}}$ and $\mathrm{y}_{\mathrm{i}}$ is:

$F\left(u_{i}, y_{i}\right)=\int_{0}^{u_{i}} \int_{0}^{4 y_{i}-2-\tilde{u}_{i}} e^{-\widetilde{u}_{i}-\varepsilon_{i}} d \varepsilon_{i} d \tilde{u}_{i}=\int_{0}^{u_{i}}\left(e^{-\widetilde{u}_{i}}-e^{2-4 y_{i}}\right) d \tilde{u}_{i}$

where $\mathrm{u}_{\mathrm{i}}<4 \mathrm{y}_{\mathrm{i}}-2$. The joint probability density function of $\mathrm{u}_{\mathrm{i}}$ and $\mathrm{y}_{\mathrm{i}}$ is $f\left(u_{i}, y_{i}\right)=\frac{\partial}{\partial u_{i}} \frac{\partial}{\partial y_{i}} F\left(u_{i}, y_{i}\right)=4 e^{2-4 y_{i}}$. By integrating out $\mathrm{u}_{\mathrm{i}}$, we get the probability density function of $\mathrm{y}_{\mathrm{i}}$ by itself:

$F_{Y_{i}}\left(y_{i}\right)=\int_{0}^{4 y_{i}-2} 4 e^{2-4 y_{i}} d u_{i}=4(4 y-2) e^{2-4 y_{i}}$

The conditional probability density function of $u_{i}$ given $y_{i}$ is:

$f\left(u_{i} \mid y_{i}\right)=\frac{f\left(u_{i}, y_{i}\right)}{F_{Y_{i}}\left(y_{i}\right)}=\frac{4 e^{2-4 y_{i}}}{4(4 y-2) e^{2-4 y_{i}}}=\frac{1}{4 y_{i}-2}$

when $y_{i} \geq 0.5$. In other words, the conditional probability density function of $u_{i}$ given $y_{i}$ is uniformly distributed between 0 and $4 y_{i}-2$. Therefore, the conditional expectation of $u_{i}$ is

$$
E\left[u_{i} \mid y_{i}\right]=\int_{0}^{4 y_{i}-2} \frac{u_{i}}{4 y_{i}-2} d u_{i}=2 y_{i}-1
$$

Since $v_{i}=\frac{u_{i}+\eta_{i}}{2}$ and $\eta_{\mathrm{i}}$ is independent of any of the random variables determining $\mathrm{y}_{\mathrm{i}}$,

$E\left[v_{i} \mid y_{i}\right]=\frac{E\left[u_{i} \mid y_{i}\right]+E\left[\eta_{i}\right]}{2}$

Since $\eta_{\mathrm{i}}$ is standard exponentially distributed, $E\left[\eta_{\mathrm{i}}\right]=1$. This and equation (16) imply that

$$
E\left[v_{i} \mid y_{i}\right]=\frac{2 y_{i}-1+1}{2}=y_{i}
$$


which shows that the firm's estimate of the value of the project at the end of the period is in fact an unbiased estimate.

Next, we need to determine $\mathrm{E}\left[\mathrm{y}_{\mathrm{i}}\right]$. To do so, we can take expectations of both sides of (17) to get $E\left[E\left(v_{i} \mid y_{i}\right)\right]=E\left[y_{i}\right]$ which gives $\mathrm{E}\left[\mathrm{v}_{\mathrm{i}}\right]=\mathrm{E}\left[\mathrm{y}_{\mathrm{i}}\right]$. Since $\mathrm{E}\left[\mathrm{v}_{\mathrm{i}}\right]=1, \mathrm{E}\left[\mathrm{y}_{\mathrm{i}}=1\right.$.

Our last task is to determine $E\left[\tilde{v}_{i}\right]$ where $\tilde{v}_{i} \equiv \max \left(y_{i}, 1+r\right)$ :

$$
\begin{aligned}
& E\left[\tilde{v}_{i}\right]=E\left[\max \left(y_{i}, 1+r\right)\right] \\
& =E\left[y_{i}\right]-\int_{0}^{4(1+r)-2} \int_{0}^{4(1+r)-2-u_{i}} y_{i} e^{-u_{i}-\varepsilon_{i}} d \varepsilon_{i} d u_{i}+\int_{0}^{4(1+r)-2} \int_{0}^{4(1+r)-2-u_{i}}(1+r) e^{-u_{i}-\varepsilon_{i}} d u_{i} d \varepsilon_{i} \\
& =1-\int_{0}^{4(1+r)-2} \int_{0}^{4(1+r)-2-u_{i}} \frac{u_{i}+\varepsilon_{i}+2}{4} e^{-u_{i}-\varepsilon_{i}} d \varepsilon_{i} d u_{i}+(1+r) \int_{0}^{4(1+r)-2} \int_{0}^{4(1+r)-2-u_{i}} e^{-u_{i}-\varepsilon_{i}} d u_{i} d \varepsilon_{i} \\
& =1-\int_{0}^{4(1+r)-2}\left(\frac{3+u_{i}}{4} e^{-u_{i}}-\frac{4 r+5}{4} e^{2-4(1+r)}\right) d u_{i}+(1+r) \int_{0}^{4(1+r)-2}\left(e^{-u_{i}}-e^{2-4(1+r)}\right) d \varepsilon_{i} \\
& =1-\left(1-4(1+r)^{2} e^{2-4(1+r)}\right)+(1+r)\left(1-(4 r+3) e^{2-4(1+r)}\right) \\
& =4(1+r)^{2} e^{2-4(1+r)}+(1+r)\left(1-(4 r+3) e^{2-4(1+r)}\right) \\
& \left.=(1+r)(1+[4(1+r)-4 r-3)] e^{2-4(1+r)}\right) \\
& =(1+r)\left(1+e^{2-4(1+r)}\right)
\end{aligned}
$$

